\title{
The Potential of Earth Observation Based Indicators to Assess the State of Urban Environment: An Application for the Urban Agglomeration of Athens
}

\author{
Constantinos Cartalis, Marina Stathopoulou \\ Department of Environmental Physics, University of Athens, Athens, Greece \\ Email: ckartali@phys.uoa.gr
}

Received 25 January 2016; accepted 11 March 2016; published 14 March 2016

Copyright (C) 2016 by authors and Scientific Research Publishing Inc.

This work is licensed under the Creative Commons Attribution International License (CC BY). http://creativecommons.org/licenses/by/4.0/

(c) (i) Open Access

\begin{abstract}
Earth observation (EO) provides the opportunity for periodic and spatially detailed assessment of the state of the environment in urban areas. In this study, the potential of EO based indicators (EI) to assess the state of environment in the urban agglomeration of Athens (UAA) is examined. EO based indicators as used in the study, include land surface temperature, land use, land cover and aerosols distribution. The indicators are also related to the household density and population density, as extracted from census data, for the same area. Indicators are applied at the municipal scale and are also used to estimate an aggregate environmental indicator (AEI), at municipal scale, by integrating all indicators mentioned above in a GIS environment. It is found that the urban agglomeration of Athens is practically "dichotomized", by being divided in a western and eastern area, with considerably different environmental conditions. Results are considered important for focused interventions supporting environmental urban planning, whereas they represent the high potential of EO based indicators to monitor and assess the state of the urban environment.
\end{abstract}

\section{Keywords}

Environmental Indicators, Earth Observation, Urban Environment, Environmental Protection

\section{Introduction}

The explosive growth of cities has led to the demand for cities to become green. To this end, the frequent assessment of the environmental conditions in a city is highly important, as it enables the monitoring of progress

How to cite this paper: Cartalis, C. and Stathopoulou, M. (2016) The Potential of Earth Observation Based Indicators to Assess the State of Urban Environment: An Application for the Urban Agglomeration of Athens. Journal of Geoscience and Environment Protection, 4, 29-37. http://dx.doi.org/10.4236/gep.2016.43003 
as well as it provides information to local authorities on the needed policies to resolve environmental problems [1].

An approach of interest is to describe the state of the urban environment by defining indicators reflecting changes in the physical and built environment [1] [2]. Such indicators may be easily, widely and effectively assessed by citizens, as well as by governing bodies, by means of Information and Communication Technologies (ICT).

Several efforts have been made to this direction as based on the combined use of environmental, social and economic indicators [3]-[7]. In [8], a methodology for an aggregate Quality of Life indicator is described; the methodology is based on the combination, with the use of varying weighting factors, of environmental, social and economic indicators.

In this study, the methodology as described in [8] is applied for the overall UAA (as depicted in Figure 1) by means of estimating the annual average values of EO based indicators (see Table 1). UAA reflects an area of $419 \mathrm{~km}^{2}$ and comprises of 40 Municipalities. The population of UAA according to the census of 2011 accounts for 3.181.872 inhabitants, with the Municipality of Athens contributing by 664.046 inhabitants and covering an area of $39 \mathrm{~km}^{2}$. UAA reflects a multitude of land cover types, with the type "urban fabric" clearly dominating. Environmental pressures of UAA are mainly urban expansion, lack of green areas, aged building stock, intense anthropogenic heat sources (predominantly transport) and increased levels of aerosols. Due to the above pressures, the Master Plan of Athens (2011) introduces the concept of the compact city, in an obvious effort to adverse urban expansion, retains inhabitants in the city centre and attracts new investments in UAA.

Table 1 provides the EO based environmental indicators as well as: (a) the type of satellite data used for each environmental indicator (b) the averaging period of the satellite data as per environmental indicator and (c) the spatial resolution of the satellite data used for the estimation of the indicators at the municipal level.

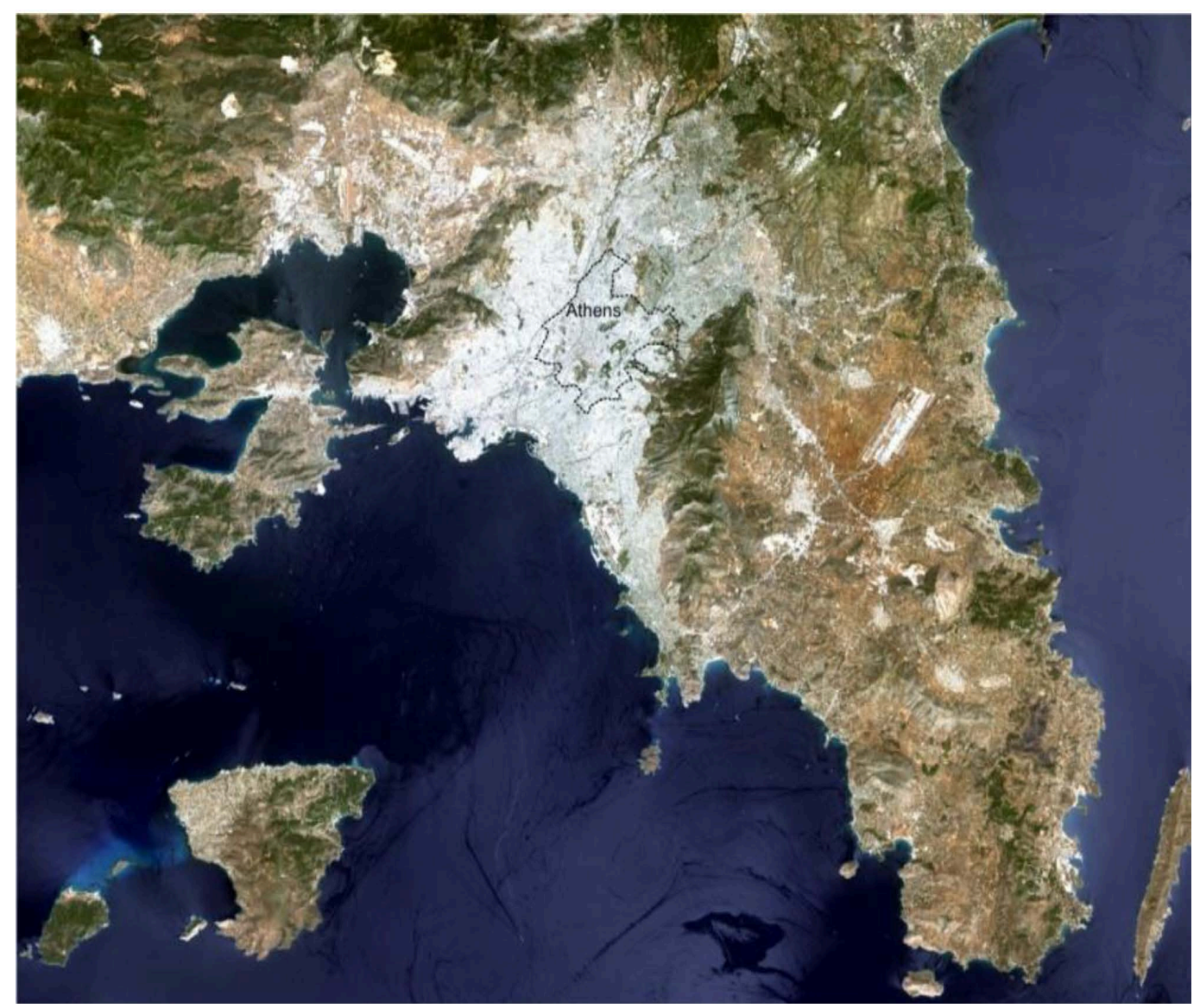

Figure 1. Spatial representation of the area of study (urban agglomeration of Athens) in yellow. Municipalities are delineated accordingly. 


\section{Methodology}

\subsection{Assessment of the Urban Expansion in UAA}

The urban expansion of UAA was estimated with the use of Lands at optical data for the period 1987-2010 [9]. Such information is considered necessary in order to assess the overall pressure in the area concerned, over a considerable period of time. As seen in Figure 2, UAA has expanded to the north and the east, with the expansions reflecting an area of roughly $80 \mathrm{~km}^{2}$.

\subsection{Data Processing}

For the purposes of this study, Lands at images were used in the visible (VIS) and thermal infrared (TIR) spectral regions. The VIS band allows the detection of land use and land cover (LULC) and the estimation of the Normalized Difference Vegetation Index (NDVI) [10]. TIR is suitable for detecting and mapping the LST variations at the selected scale [11]-[13]. In particular, a classification of the satellite images was performed, on the basis of the following categories of land cover: (a) urban fabric (including continuous and discontinuous urban fabric), (b) Artificial non-agricultural vegetated areas (including green urban areas, sport \& leisure facilities), (c) urban use areas (including industrial/commercial units, road/rail networks \& associated land, port areas, airports, mineral extraction sites, dump and construction sites), (d) agricultural areas, (e) forests and semi-natural areas, and (f) water surfaces.

Table 1. A description of the earth observation based environmental indicators.

\begin{tabular}{|c|c|c|c|}
\hline Earth observation based environmental indicator & Type of satellite data & Averaging period & Spatial resolution \\
\hline Land surface temperature & Thermal & 16 days & $120 \mathrm{~m}$ \\
\hline Vegetation & Optical & 16 days & $30 \mathrm{~m}-1 \mathrm{~km}$ \\
\hline Aerosols distribution & Optical & 3 days & $300 \mathrm{~m}$ to $1.2 \mathrm{~km}$ \\
\hline Land use & Optical & 30 days & $30 \mathrm{~m}$ \\
\hline Land cover & Optical & 30 days & $30 \mathrm{~m}$ \\
\hline Urban expansion/sprawl & Optical & 6 months & $30 \mathrm{~m}$ \\
\hline
\end{tabular}

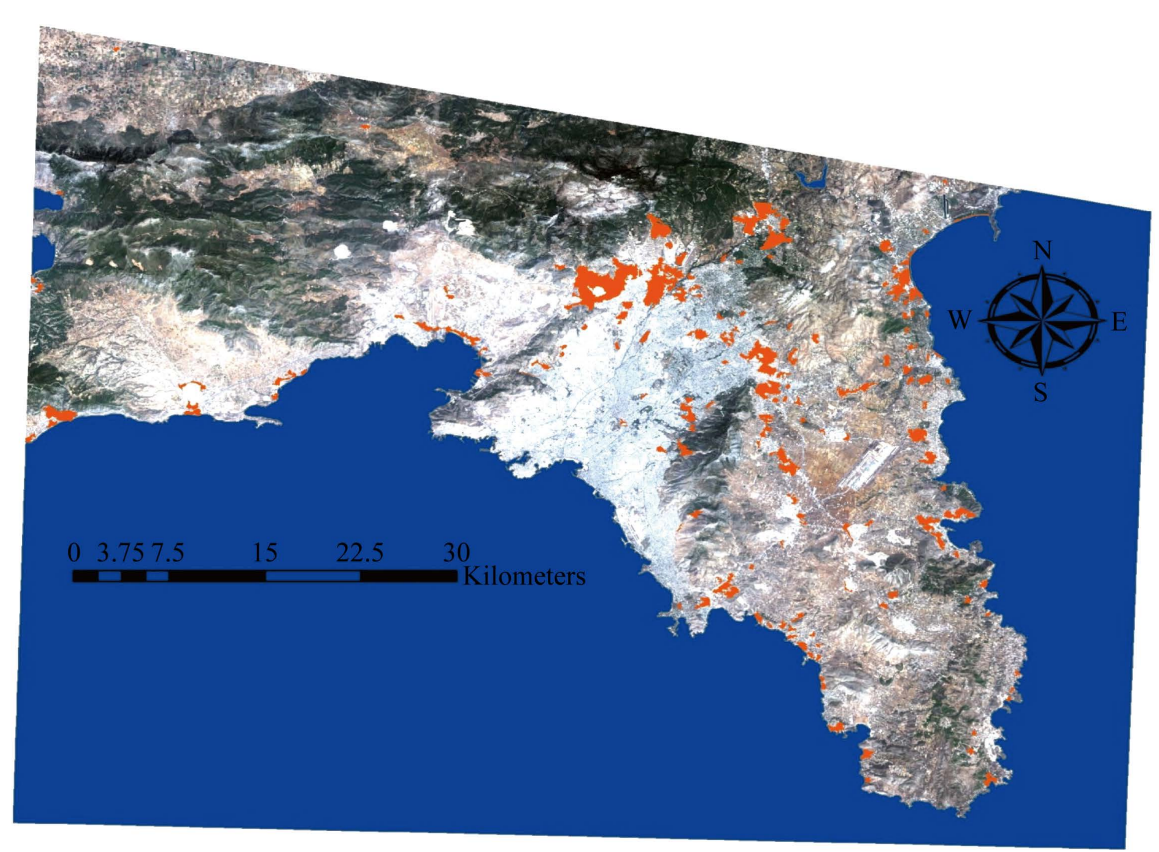

Figure 2. Areas in orange reflect the urban expansion of the urban agglomeration of Athens for the period 1987-2010. 
The concentration of aerosols (PM 10) in the UAA was estimated in an indirect manner, by means of the optical depth as derived with the use of MERIS/ENVISAT satellite data [14]. Finally, the area per municipality referring to category "urban fabric" was used to estimate the population density and the household density, also with the use of census data for UAA.

\subsection{Classification of EO Based Environmental Indicators}

\subsubsection{Land Surface Temperature (LST)}

LST is regarded as a negative indicator of the physical environment of Athens, as previous studies have shown that high LST values have negative impact on urban climate [15] [16], increase human thermal discomfort [16] and energy demand [17].

\subsubsection{Green Areas}

NDVI is regarded as a positive indicator of the physical environment of metropolitan Athens as it can provide many aesthetic and environmental benefits to the citizens.

\subsubsection{Land Cover}

The category "urban use" was regarded as a negative indicator of the physical environment as extended concentration of such infrastructures within their municipality may lead to the deterioration of their quality of life.

\subsubsection{Aerosols Concentration}

The concentration of aerosols is regarded as a negative indicator of the physical environment of Athens, as previous studies have shown that high concentrations of aerosols values have a negative impact on urban health and urban climate [18].

\subsection{Population and Household Density}

Both indicators were considered negative as they result in increase of anthropogenic heat sources in UAA, thus enhancing the urban heat island phenomenon and resulting in higher energy consumption for cooling.

\subsection{Estimation of the Aggregate Environmental Indicator}

The municipality vector map was overlaid to the LST, NDVI, urban use, aerosols, population density and household density maps, whereas mean values of all indicators were calculated per municipality. These values were then integrated in a GIS; for fair comparison between AEI in different years, all indicator values were normalized in the range 0 to 1 . In case of a positive indicator, for example vegetation, the value of 0 indicates the least positive influence on the AEI of citizens-practically implying a negative impact on EI-whereas the value of 1 represents the most positive influence on the AEI. Likewise, in case of a negative indicator such as LST, the value of 1 indicates the worst influence on AEI in contrast to the value of 0 which implies the least negative impact on EI. On the basis of the hypothesis that all indicators affect equally the AEI, all indicator values were added up resulting in a score for AEI for each municipality. The score was also normalized in the range 0 to 1 and was further classified into five equal intervals termed as levels: low, fair, moderate, good and high.

The process described in Section 2 is schematically provided in Figure 3.

\section{Results and Conclusions}

In this section, representative monthly results of the EIs are provided, as averaged at the Municipality level. Figure 4 and Figure 5 present the distribution of Land Surface Temperature (Kelvin) and NDVI in the Municipalities of UAA. Higher LST values are observed in the western Municipalities, whereas lower ones in the Municipalities to the north of the city. An explanation for such differences may be the difference in the quality and age of the building stock as well as the lower and higher NDVI values as found in the Municipalities to the west and north respectively. Results are also directly related to the urban use (Figure 6) and to the population density (Figure 7) as clearly seen for the Municipalities to the west of UAA.

Figure 8 presents the aerosols distribution $\left(\mu \mathrm{gr} / \mathrm{m}^{3}\right)$ per Municipality, whereas Figure 9 presents the spatial variation of the aggregate EI. 


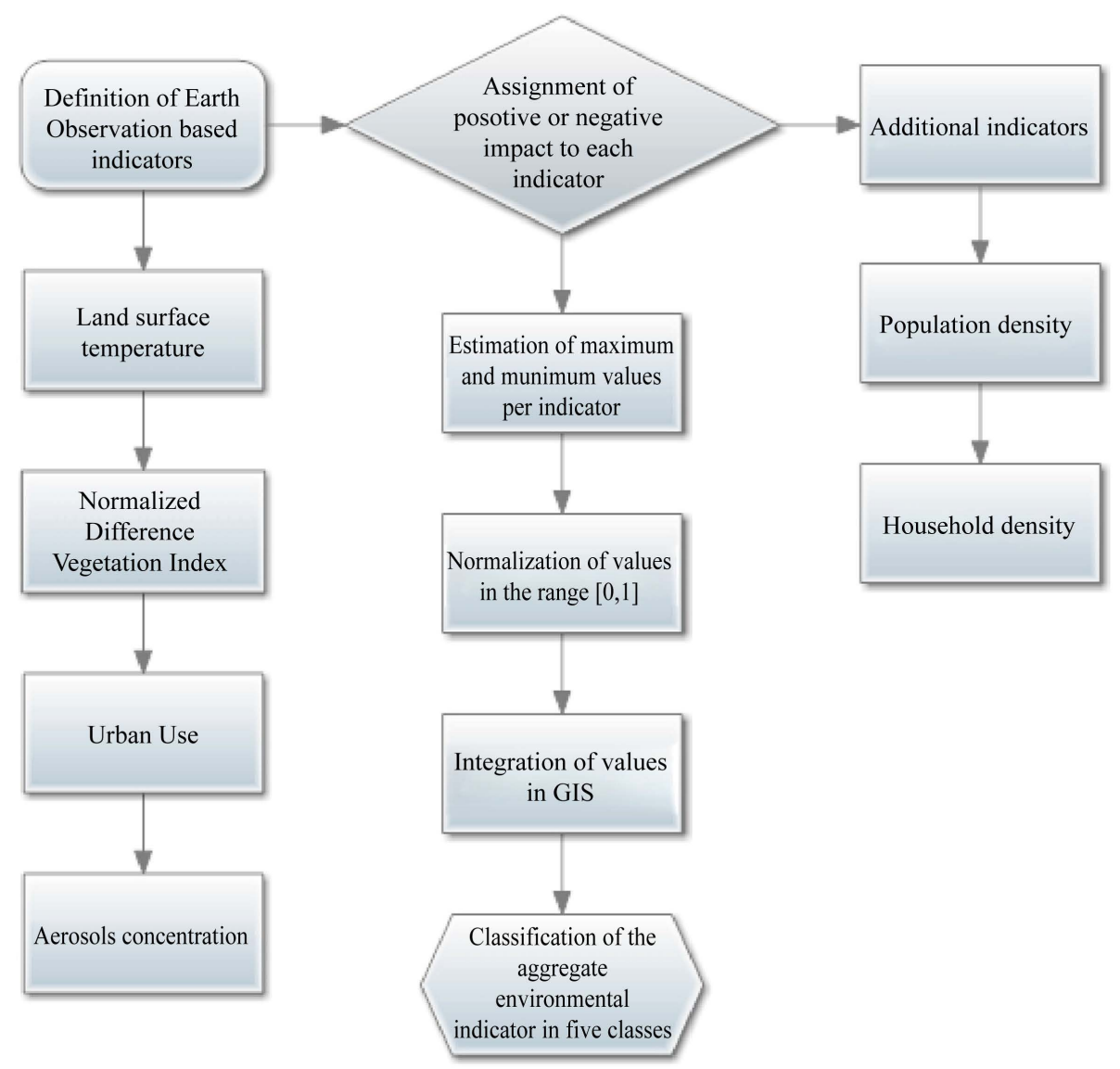

Figure 3. Flow chart of the methodology in support of the estimation of the Aggregate Environmental Indicator (AEI).

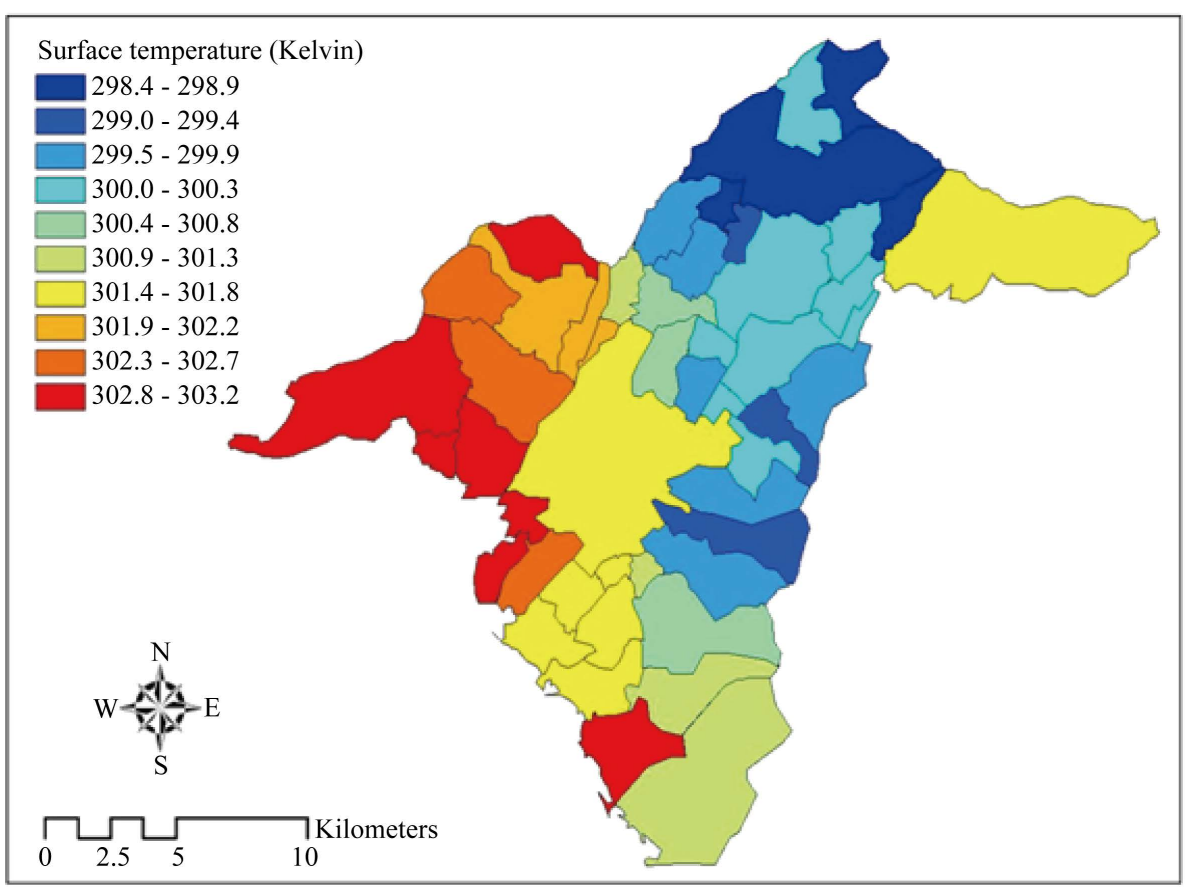

Figure 4. Distribution of Land Surface Temperature in the urban agglomeration of Athens. 


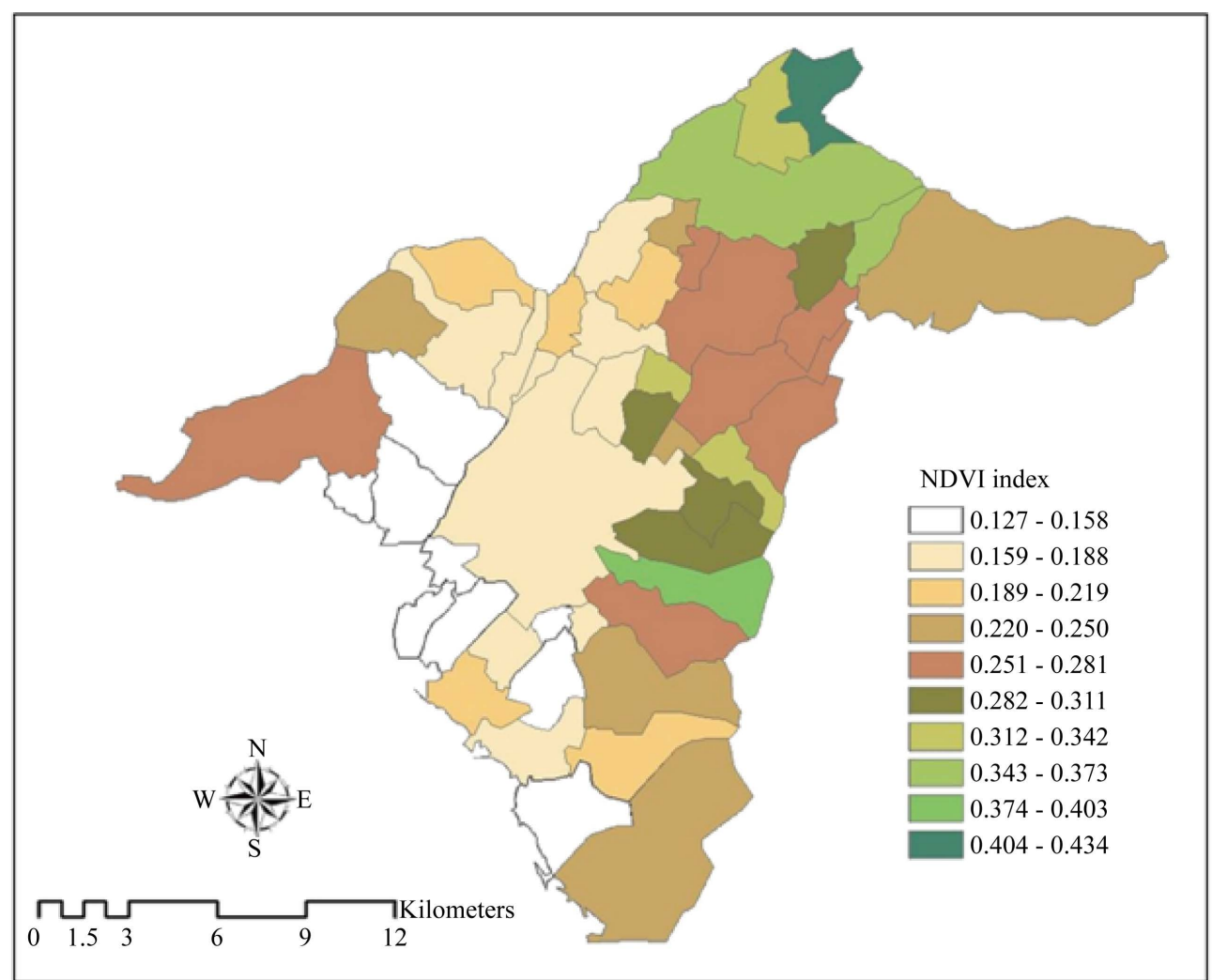

Figure 5. Distribution of NDVI in the urban agglomeration of Athens.

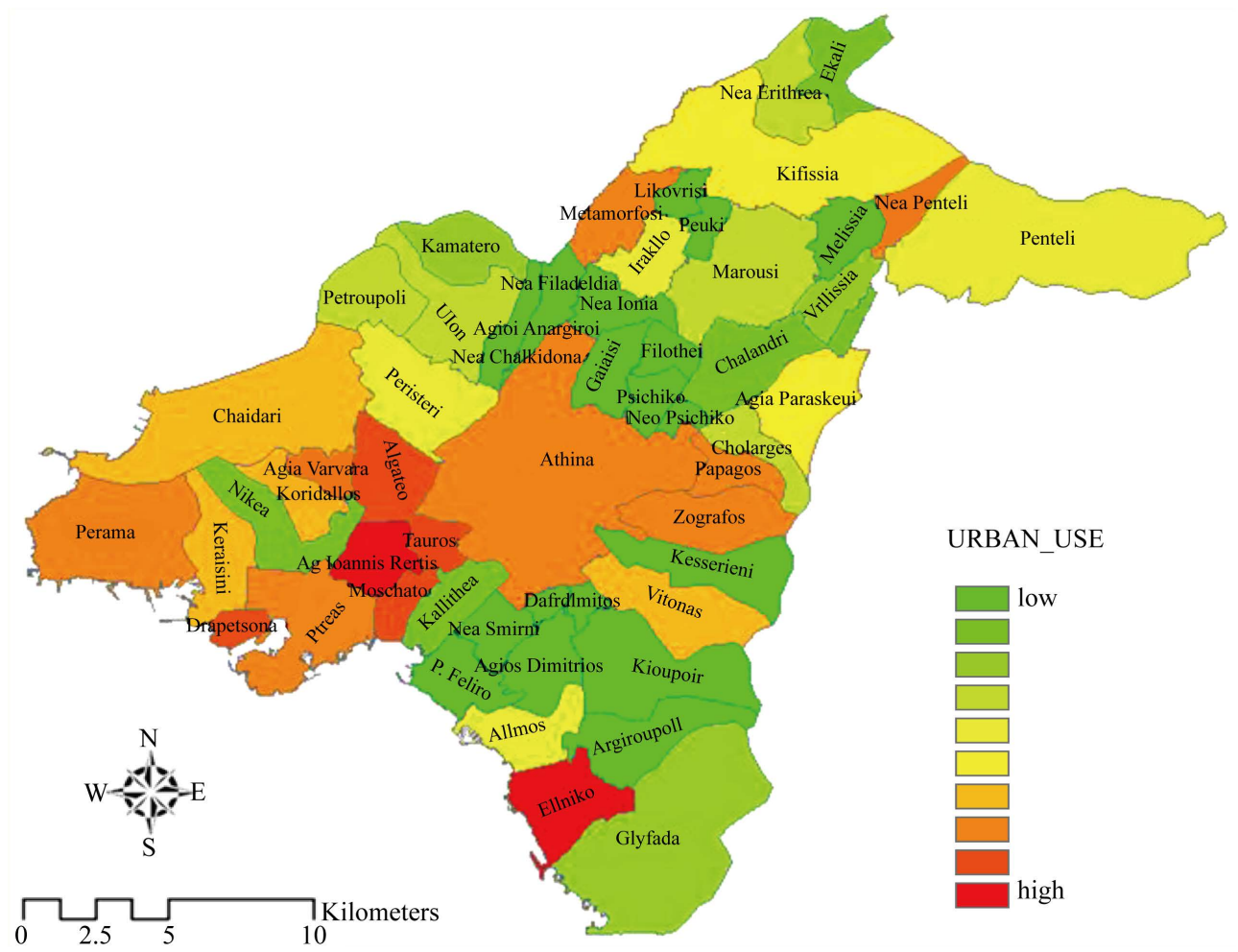

Figure 6. Urban use (\%) defined as land cover reflecting industrial/commercial/transport units/mineral extraction sites/dump and construction sites. 


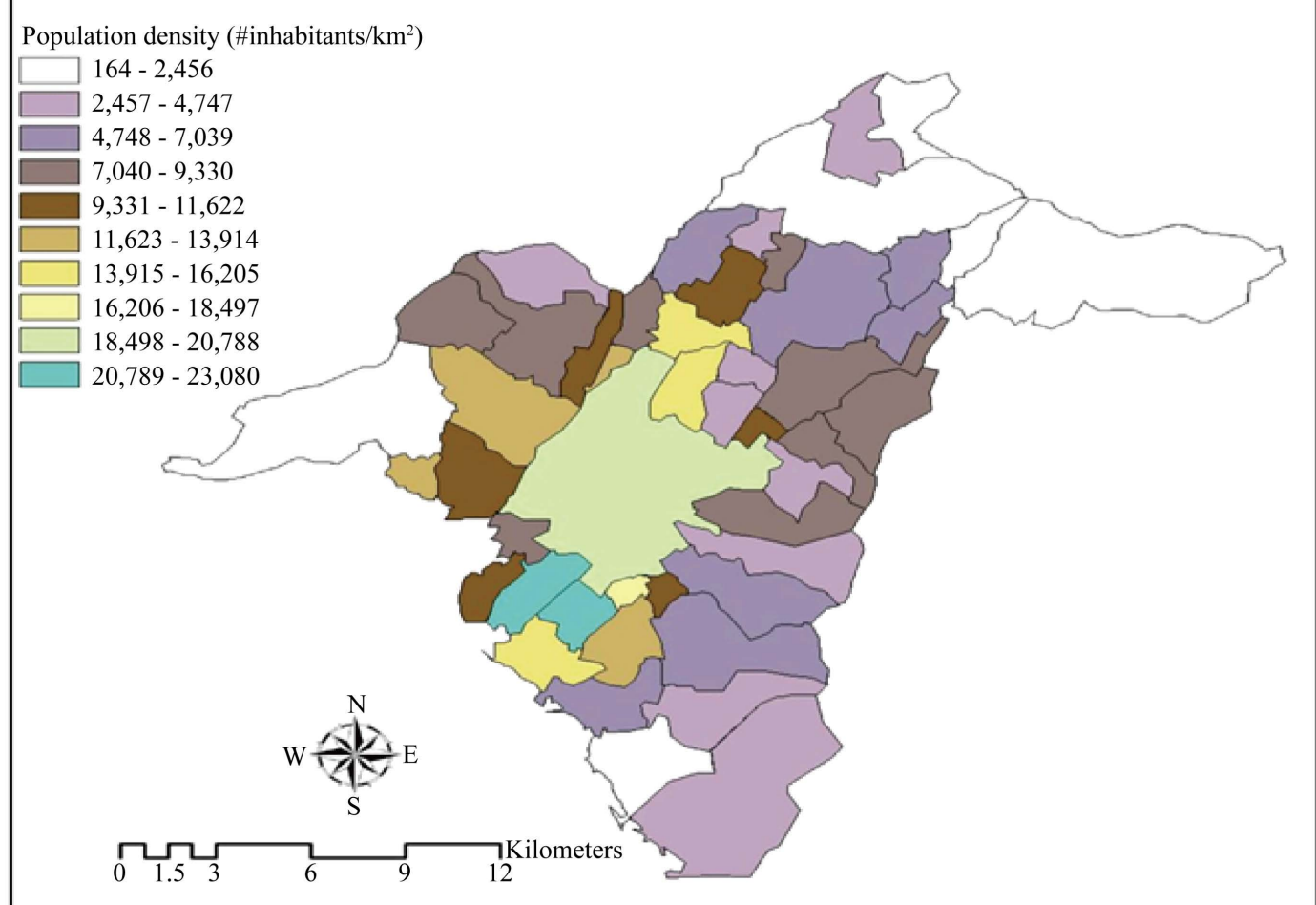

Figure 7. Population density (\# inhabitants per $\mathrm{km}^{2}$ ).

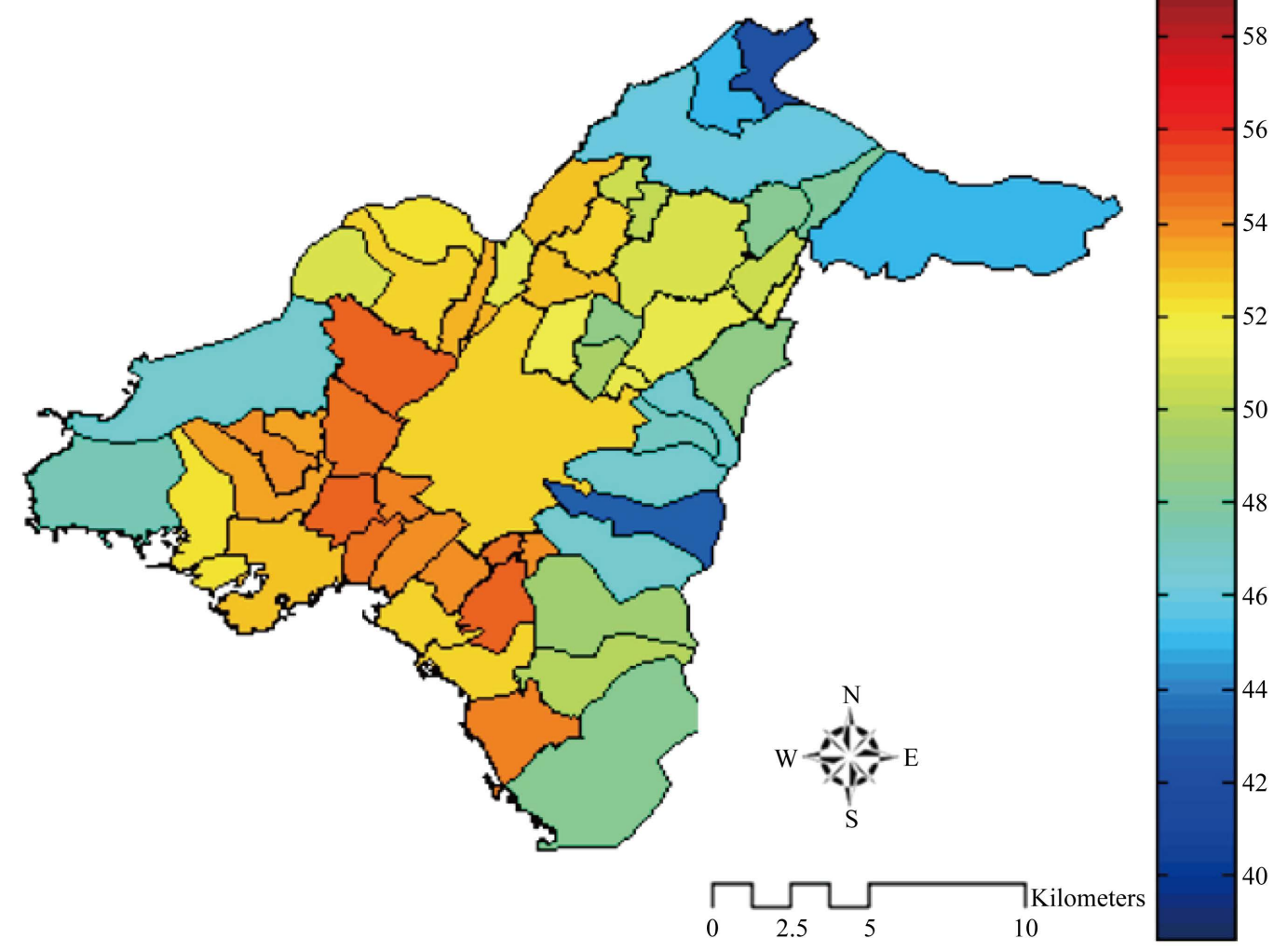

Figure 8. Concentration of aerosols (in $\mu \mathrm{gr} / \mathrm{m}^{3}$ ) in the urban agglomeration of Athens. 


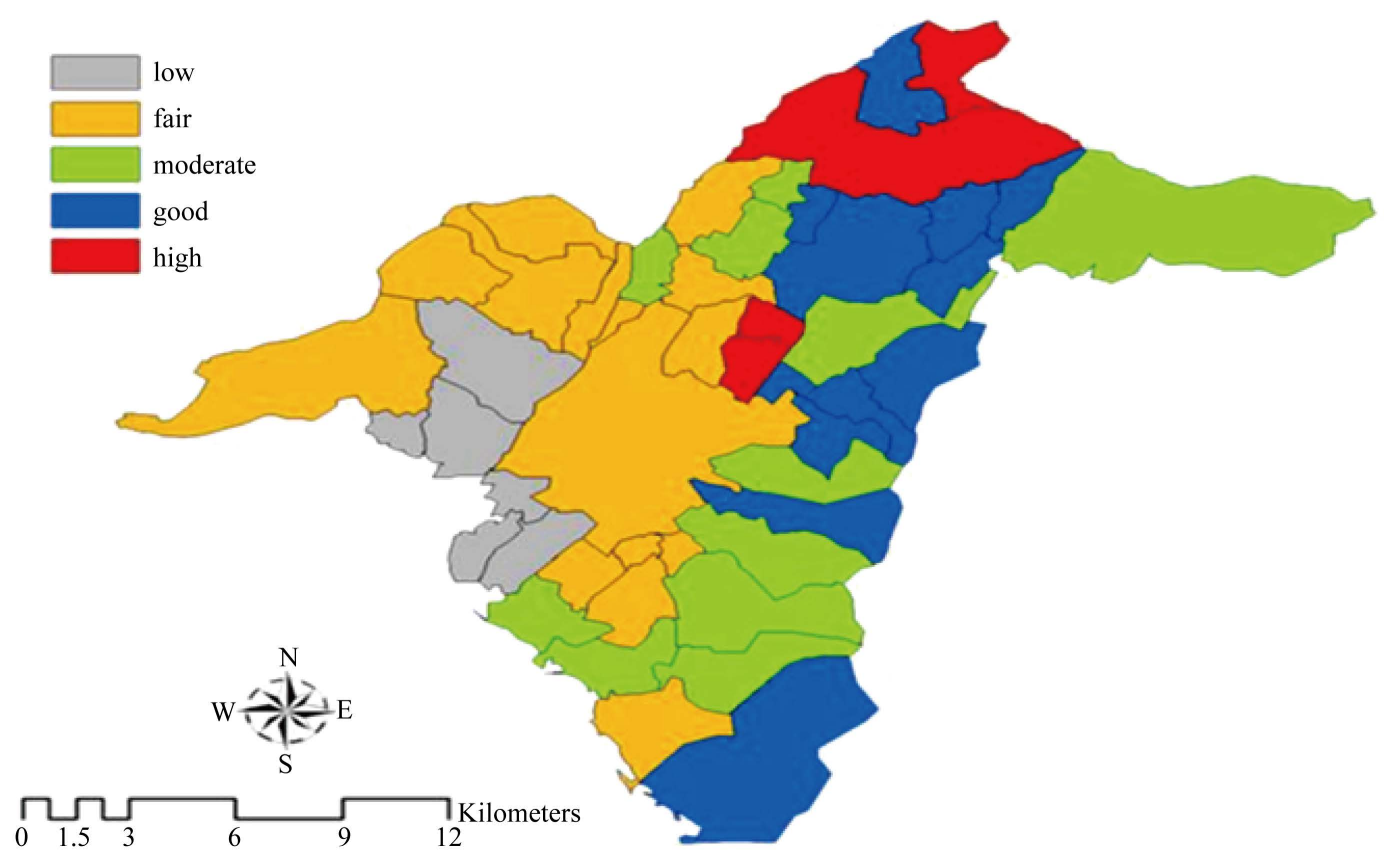

Figure 9. Mapping of the aggregate Environmental Indicator in the urban agglomeration of Athens.

An examination of Figure 9, yields a number of interesting findings: (a) the western Municipalities of the UAA obtain low/fair values for the AEI, as expected due to the high LSTs, low NDVIs, high percentage of urban uses and increased concentrations of aerosols (b) urban expansion to the west of the city is associated with low/fair values of AEI; on the contrary, urban expansion to the north or east parts of the city is associated with moderate/good values of AEI and (c) the urban agglomeration of Athens is "dichotomized" in terms of AEI, along a theoretical axis from the northeast to the southwest (higher AEI to the east of the axis, lower AEI to the west).

The results of this study are considered satisfactory, in the sense that they show that EO based environmental indicators as well as the aggregate environmental indicator can provide a reliable assessment of the state of environment in urban areas. It should be mentioned that the use of more environmental indicators will favor a more synthetic determination of AEI. Additional indicators to be used may be ozone concentration, air temperature and energy consumption per household or $\mathrm{km}^{2}$.

\section{Acknowledgements}

This paper was partially supported by the ESA-MOST Dragon program.

\section{References}

[1] European Environment Agency (2012) Environmental Indicators Report. 151 p.

[2] Chrysoulakis, N., Lopes, M., San Jose, R. and Cartalis, C. (2013) Sustainable Urban Metabolism as a Link between Bio-Physical Sciences and Urban Planning: The BRIDGE Project. Landscape and Urban Planning, 112, 100-117. http://dx.doi.org/10.1016/j.landurbplan.2012.12.005

[3] Dow Jones Sustainability Indices (2014) http://www.sustainability-indices.com/

[4] Environmental Protection Agency (2012) A Framework for Sustainability Indicators at EPA. EPA/600/R/12/687, 59.

[5] Moldan, B., Janoušková, S. and Hak, T. (2012) How to Understand and Measure Environmental Sustainability: Indicators and Targets, Ecological Indicators, 17, 4-13. http://dx.doi.org/10.1016/j.ecolind.2011.04.033

[6] Quality of Life Indicators Project (2002) Quality of Life in Canada-A Citizens’ Report Card. Canadian Policy Research Network, Ottawa.

[7] Morton, P. (1999) Quality of Life in Saskatoon 1991 and 1996: A Geographical Perspective. MA Thesis, University of Saskatchewan. 
[8] Stathopoulou, M., Iakovides, S. and Cartalis, C. (2012) Quality of Life in Metropolitan Athens, Using Satellite and Census Data: Comparison between 1991 and 2001. Journal of Heat Island Institute International, 7-2, 25-33.

[9] Charalampopoulos, I. (2014) Assessment of Land Use Change in the Attica Region from 1987 to 2010. MA Thesis, University of Athens.

[10] Masek, J.G., Lindsay, F.E. and Goward, S.N. (2000) Dynamics of Urban Growth in the Washington DC Metropolitan Area, 1973-1996, from Landsat Observations. International Journal of Remote Sensing, 21, 3473-3486. http://dx.doi.org/10.1080/014311600750037507

[11] Chander, G. and Markham, B. (2003) Revised Landsat-5 TM Radiometric Calibration Procedures and Postcalibration Dynamic Ranges. IEEE Transactions on Geoscience and Remote Sensing, 41, 2674-2677. http://dx.doi.org/10.1109/TGRS.2003.818464

[12] Sobrino, J.A., Jimenez-Munoz, J.C. and Paolini, L. (2004) Land Surface Temperature Retrieval from LANDSAT TM 5. Remote Sensing of Environment, 90, 434-440. http://dx.doi.org/10.1016/j.rse.2004.02.003

[13] Stathopoulou, M. and Cartalis, C. (2007) Study of the Urban Heat Island of Athens, Greece during Daytime and Night-Time. Proceedings of the 2007 Urban Remote Sensing Joint Event (IEEE) Conference, Paris, 11-13 April 2007, $1-7$.

[14] Kaskaoutis, D.G., Sifakis, N., Retalis, A. and Kambezidis, H.D. (2010) Aerosol Monitoring over Athens Using Satellite and Ground-Based Measurements. Advances in Meteorology, 2010, Article ID: 147910. http://dx.doi.org/10.1155/2010/147910

[15] Stathopoulou, M., Cartalis, C. and Chrysoulakis, N. (2006) Using Midday Surface Temperature to Estimate Cooling Degree-Days from NOAA-AVHRR Thermal Infrared Data: An Application for Athens, Greece. Solar Energy, 80, 414422. http://dx.doi.org/10.1016/j.solener.2005.02.004

[16] Stathopoulou, M., Cartalis, C., Keramitsoglou, I. and Santamouris, M. (2005) Thermal Remote Sensing of Thom's Discomfort Indicator (DI): Comparison with in Situ Measurements. Proceedings of the Remote Sensing 2005 Symposium, (SPIE 2005), 5983, 254-258.

[17] Santamouris, M., Papanikolaou, N., Livada, I., Koronakis, I., Georgakis, C., Argiriou, A. and Assimakopoulos, D. (2001) On the Impact of Urban Climate on the Energy consumption of Buildings. Solar Energy, 70, 201-216. http://dx.doi.org/10.1016/S0038-092X(00)00095-5

[18] WHO (2014) Ambient (Outdoor) Air Quality and Health. http://www.who.int/mediacentre/factsheets/fs313/en/

\section{Nomenclature}

EI: Environmental Indicator; AEI: Aggregate Environmental Indicator; UAA: Urban Agglomeration of Athens; EO: Earth Observation; LST: Land Surface Temperature; NDVI: Normalized Difference Vegetation Indicator 